\title{
Tunisian Labor Market and Regional Heterogeneity: Application of PSTR Model
}

\author{
Yosra Koubaa \\ LaREMFiQ-IHEC, Sousse University \\ B.P. 40 Route De La Ceinture, Sahloul III, Sousse 4054 \\ Tunisia \\ E-mail: yosra.koubaa@yahoo.fr
}

Received: December 12, 2016

Accepted: January 12, 2017 Published: January 15, 2017

doi:10.5296/ijrd.v4i1.10299

URL: http://dx.doi.org/10.5296/ijrd.v4i1.10299

\begin{abstract}
This paper is devoted to investigating the matching process for Tunisia using desaggregated data by assuming that the rising of the unemployment rate result from regional disparities which yield variation of matching efficiencies across regions. Since most econometric aspects of spatial heterogeneity can be handled by means of the standard panel data methods, we focus our discussion on the new technique: Panel Smooth Transition Regression models (PSTR). The distinction is that we can compute regional specific sensibilities for 23 regions over the period 1984-2004. Given this objective, we consider three structural factors that allow explaining the regional imbalances. Contrary to the previous econometric techniques of the matching theory, estimates of the coefficients depend, of three transition variables. The results show that women insertion, the qualification share and population density significantly contribute to explain the asymmetry of the matching process across regions. Our main conclusion is that the hiring in Tunisia is driven essentially by the stock of vacancies about is the region. The willingness of job seekers, obviously, remains low, although it is different between regions and seems relatively important in urban zones.
\end{abstract}

Keywords: Unemployment, Asymmetry, Matching-process, PSTR Model

\section{Introduction}

In January 14th 2011 a whole system was tipped over, a persistent unemployment (World Bank (2004)) and regional imbalances were the spark of the Tunisian revolution. Despite its economic growth and economic performance, the authoritarian bargain between the regime and society in Tunisia, broke down due to the growing inability of the economy to create jobs for educated labour, the proliferation of marginal and poorly paid jobs in the informal sector 
and the regional disparities. According to the BCT (Central Tunisian Bank, (2009)), the unemployment rate had reached 13.3 percent in 2009 and had steadily increased from 12.5 percent in 2006. In addition, with more than 500,000 job seekers this rate remains one of the highest in the MENA region. The unemployment rate of young graduates was neighbored to 30 percent for ages less than 30-year old in 2004. It has risen dramatically from 16.9 percent in 2006 to 21.9 percent in 2009 and it was remaining high despite the employment policies which implemented in Tunisia since 1990 to insert the young seekers. By the end of 2010, almost one of four university graduates are unemployed. This situation is typical for countries where the education and training system is not adequate to the economic environment.

During the last decade, there have been many attempts to activate the tertiary sector (e.g., transport, communication) and other sectors such as fisheries, mines and energy but without much success. These policies have mainly focused on attracting foreign direct investment often requiring few skills and induced a potential for highly educated emigration such as the doctors and engineers to the Golf States and with a lesser extent to Europe.

The potential causation from the existence and the persistence of regional disparities to aggregate unemployment rate constitute the second most striking feature of Tunisian labor market. The concentration of investment in the coastal zones with a low geographic mobility, higher cost and lack of information are viewed the main causes of this disequilibrium and they aggravated the aggregate unemployment. The economic perspectives for job creation were already focused on the axis coast (North-East, Central and Eastern District of Tunis) which generated the outnumbering of job seekers in the disadvantaged regions. In 2004, the Tunisian unemployment rate registered a nominal value in the Center East of 10 percent where the regions have a diversified and active economy such as Monastir but it reached its most worst value in the North West (a modest agricultural activity such as Jendouba and Elkef) and in South West (mining regions: Gafsa, Metloui).The trend has not changed much in recent years, in 2007 for example the South -West and the North West have higher rates of unemployment (around 20 percent). They are followed by the Midwest and Southeast who have rates above 14.1 percent. According to Boubakri (2010), more than the half of the governorates has rates above the national unemployment average (14.1 percent in 2007 (INS)) such as for example: Jendouba, Siliana, Gasserine, Gafsa. It is therefore important to revising the policy guidelines for investment in human capital by studying the specific characteristics of job-seekers across the regions.

In theoretical view, unemployment disparities are mostly interpreted as a result of limited interregional labour mobility or as differences in the underlying factors of the regional labour market. In most search models, say for example Diamond (1982), it is suggested that a spatial dispersion of units creates more frictions and thus more unemployment. According to Jackman, Layard and Pissarides (1989), L'Horty (1997) and Sneessens et al (2002), the regional imbalances are analyzed as a first explanation of matching inefficiency.

Several empirical analyses have been advanced in the literature, the first one, such as Blanchard and Diamond (1989), Pissarides (1986), Layard et al (1991), (1995), consists in estimating the matching function on aggregated data where the variables are structured as 
time series which ignore regional disparities. Another strand of research, such as that of Cole and Smith (1996), Anderson and Burgess (2000), Kangasharju et al. (2005), Hynnienen (2005), Kano and Ohta (2005) showed how the matching inefficiencies and the regional disparities in structural factors contribute to regional and aggregate unemployment. They considered the specification with regional data was very interesting since it control such observable and latent heterogeneity across regions and correct the aggregation error.

Despite the many theoretical models analyzing the sources of frictions, the empirical literature on the determinants of the efficiency process market is still uncommon, particularly for the developing countries Drin and Bouabid (2011). At the same time, although the problem of spatial aggregation is discussed, the results from a data panel methodology don't invalidate the previous results, on the aggregate time series basis. It can be attributed to a bad specification of used econometric technique.

Both in the cross-regions studies and the panel data methodology, imposing that the parameters are homogeneous across regions is a very strong assumption. For that purpose, we propose a model which allows the sensibilities of hiring to vary across regions. The cross-regions heterogeneity of hiring can be analyzed as the consequence of threshold effects. At each instant, in the threshold model, the regions are divided into a specific regional model or a small number of classes with the same sensibilities according to an observable variable. The threshold variable can be defined as the level of interesting features of job seekers. However, the main difference is that the hiring is then endogenously determined by the threshold model. The main contribution of this paper is devoted to estimating the PSTR (Panel Smooth Transition) for Tunisian regional data which allows for threshold effects in the relationship of the matching process. These specifications suppose that the coefficients vary between regions and continuous in the time which allows to capture both cross-regions heterogeneity and time-varying sensibilities. For instance, we retain three factors to explain the cross-regions disparities and the time-varying coefficients in the matching function in Tunisia. Let us note besides that the choice of factors in this work is bounded to the available data.

The remainder of this article is organized as follows. The first section defines the matching theory. In the second section, we present the methodology and specification tests for PSTR models. The third section is given over to the results as well as interpretation of these estimates from various models and the individual parameters. The section 4 concludes.

\section{Matching process and PSTR Specification}

In a labour market with search frictions, both unemployed and firms are involved in a costly and time-consuming process of searching the appropriate match. This complex process can be summarized by a well-behaved matching function.

Like the micro-economic approach of Blanchard and Diamond (1989) and Petrongolo and Pissarides (2001), the matching function enables modeling role of frictions in labour market with a minimum of complexity.

The standard aggregate function of matching (see Blanchard and Diamond (1989)), had been 
estimated on aggregated data where it was imposed the strong assumption of homogeneity of friction effects between different sub-markets and Constance of returns to scale (e. g. Pissardies, 2000). In contrast to recent empirical studies in cross-sectional analysis such as Cole and Smith (1996) and Anderson and Burgess (2000), considered that the specification of regional data is better to understand the dynamics of the matching process sub-market when the data set is des-aggregated. However, changes in the quantitative efficiency with which a match occurs are not likely to keep constant the returns to scale over time. Shifts in the matching function occur as the factors (that affect the efficiency level) which are themselves subject of the change.

A simplest theoretical version of the matching process generally takes the following functional form of Cob-Douglas where the flow of new hires is related to the stock of unemployment and vacancies:

$$
H_{t t}=A_{t t} U_{t t-1}^{\beta_{t}} V_{t t-1}^{\beta_{t}} \varepsilon_{t t}
$$

(1) (Note 1)

Where is $\boldsymbol{H}_{t t}$ is a new hiring at time t.

$U_{t i-1}$ denotes the level of unemployment and $V_{t t-1}$ the level of vacancies.

The marginal propensities $h_{w} \quad \hbar_{v}$ are assumed positive and decreasing (Note 2). As in appropriate production theory, $\mathrm{A}$ is a scalar parameter introduced in order to capture the total factor productivity of the function.

Empirically, the matching function can be estimated with cross-sectional variation across entities of interest like regions, occupations or sectors. Hence, it is usually specified as a linear model evaluating the flows of hiring for a panel of $\mathrm{N}$ regions. The corresponding form is then defined as follows:

$$
h_{t+t}=\mu_{t}+\beta_{1} u_{t-1}+\beta_{2} v_{t-1}+a_{t}
$$

$u_{t-1}, v_{t-1}$ represents the logarithm of job vacancies and job seekers at (t-1), respectively.

In this linear specification, like Fahr and Sunde (2002), we can introduce a time trend and possibly other control variables like occupation, age structure, occupations or group dummies enter to explain the augmented form of the matching process as follows:

$$
h_{t=}=\mu_{t}+\beta_{1} u_{t=-1}+\beta_{2} v_{t=-1}+\sum_{j}^{k} \gamma_{t j} Z_{t j=}+\theta t+a_{t t}
$$


with $Z_{i j t}$ vector of additional specific variables or dummies groups like sectors, regions, industries.

According to the linear form, a positive coefficient can be interpreted as increase of efficiency of the labor market. The opposite is true for a negative coefficient. In addition, the relative sizes of the elasticities with respect to the stock of unemployed and vacancies indicate the relative importance of labor supply and demand.

Within the empirical framework (Note 3) two modeling approaches are used. The first approach considers a panel-data model with fixed effects. This model was applied to Japanese labour data (Kano \& Ohta, 2005) and on English labour market (Cole \& Smith, 1996). They estimated a function using a cross-sectional data where the economy is considered as a collection of spatially distinct-labour market. Given this, they reported the same results by using cross-sectional data on regional-level compared to those stemming from aggregate time series data (Pissaridies, 1986). Roughly speaking, it is suggested that job seekers intensity and employers behavior during the hiring process are the main determinants of the frictions intensity in the matching-process. However, the explanations vary according different concepts of the pools of searchers, and exhibit some regional spillovers.

A second approach is used to analyze the efficiency of stochastic frontier such as the work of Ibrouk and Perelman (2001) on Morroco market, Drin and Bouabid (2011) on Tunisian market. By modifying the traditional matching model, these authors identified and assessed several factors: age, structure, education level, occupation could explain the causes of the unemployment gap observed between different regions. The effect due to the deficiencies has been represented by fixed or random effect coefficients. Besides, the major objective of the last approach was to test the constancy of scale-return.

In our purpose, these specifications seem to have some problems for three reasons. Firstly, the linear model considers the same ${ }^{u_{t}}$ and ${ }^{v_{t}}$ sensibility on ${ }^{h_{t}}$ across the $\mathrm{N}$ regions of the panel, I. e. $\beta_{t}=\beta \quad$ for all $t=1_{t=\ldots+z} A$.

However, the difference in unemployment rate across regions suggests that labour market opportunities are associated with specific regional structural characteristics. As Heynnienen et al. (2011) the regional disparity of structural factors contributes to formation of regional and aggregate unemployment. It is suggested that there would be a substantial decline in the aggregate unemployment if the regions shared the same structure of job seekers and vacant jobs.

In order to circumvent this problem and improve the simple version of the matching-function, several solutions have been advanced. One of them is the introduction of demographic, geographic or regional factors in estimating the matching function in each region such as the structural unemployment, the labour market intensity, population density (Cole \& Smith, 1996), the qualification level (Fahr \& Sunde, 2002), the share of women jobs seekers. This 
was a way with which the model could provide better evidence on the relative importance of frictions in the matching process. Drine and Bouabid (2011) tried to highlight the role of regional disparities in unemployment rates and they concluded of the importance of differences in structural factors across regions to understand in part the causes of unemployment in Tunisia. Despite the efforts to improve the microeconomic approach, the sensibility of the relationship between ${ }^{u_{t}}, v_{t}$ and ${ }^{h_{t}}$ remain common for all regions .

Second, according to theory and matching-literature, it is assumed that matching-function is $\log$ linear with constant returns $x+\beta=1$. Diamond (1982) and Pissaridies (1986), in studying the aggregate matching-function, showed that a increasing return to scale is consistent with search-externalities and multiple equilibrium. The idea is that the homogeneity on scale-return ensures the existence of a unique equilibrium in a model of equilibrium-unemployment with a endogenous search effort (see Petrongolo and Pissaridies, 2001) while a increasing return to scale make room for multiple equilibrium state of unemployment rate.

The empirical evaluation of the matching function in developed countries often display constant or slightly decreasing return to scale (Anderson \& Burgess, 2000; Burda \& Wyplosz, 1994). However, the results are more diverse for the transition countries and new EU member states (Burda, 1993; Münich et al., 2003). Unstable and rapid change of macroeconomic has made its contribution. For developing countries, the results showed constant or a slightly decreasing return to scale (Ibrouk and Perelman, 2001, Drine et al., 2011).

The last issue raised in the literature is the non stationary and or asymmetry (threshold effect) in the unemployment series, Where his dynamics is the direct implication of an asymmetric interaction between the flows of jobs and the workers. In fact, the efficiency of the matching process always has a strong effect on unemployment: the more efficient the matching, the lower the unemployment rate. The matching is altering more generally with the degree of match between the skills of workers relative to the requirements of jobs. The higher the degree of mismatch, the higher the unemployment rate Blanchard (1998).

The increased of mismatch between the vacancies and the job seekers decrease the level of hires, given the level of vacancies and unemployment. As the vacancies are filled less rapidly, the unemployment rate will rise, given the level of vacancies. Albeak and Hansen (2004) considered a smooth transition function of (Lin \& Teràsvirta, 1994) for capture the movements of the hiring function in contrast to the common practice of describing the shifts by exogenous indexes and linear trends. Their explanation is as follows: when an upturn sets in, increased labour demands results in more posted vacancies but as the matching process takes time, the unemployment move more slowly. Conversely, they showed that downturns begin with a decrease in the number of vacancies followed by a reduction in hiring where the unemployment increase.

A popular way of investigating full persistence in unemployment rates has been to test the null hypothesis that the unemployment rate has a unit root and cointegrated with a set of other 
macro variables. Thus, it is possible to consider that the unemployment rate is stationary, but would require a nonlinear model. It turns out that several studies showed that the persistence of unemployment series can be explained by the existence of the threshold effect and models them by nonlinear models (Skalin \& Teràsvirta, 2002). However, in the time series theory, it is generally supposed that unit root test based on the linear specification is likely to indicate the non stationary of the series when the true data model is a threshold model. In panel data, the results are mitigated. Phillips and Moon (1999) note that the consequences of non stationary in linear panel model are not equivalent to those generally pointed out in a time series context.

Responding to this challenge, Cupertino, Galumberti (2009) have presented threshold autoregressive panel unit root approach. In order to extend the tests of Caner and Hansen (2001) to a panel data context, their purpose is to obtain panel estimates without making the assumption of the common autoregressive. Their results showed that the threshold effect test supplant the unit root test (Note 4).

Let us focus on the asymmetry of the unemployment and hiring rate, the search and match model of Diamond (1982) is an example of a theoretical model that consider that unemployment rate can switch between a multiple equilibrium. This stylized fact of asymmetry has prompted economists to find explanations for it. Several studies have shown that the costs of hiring and firing are not symmetric; see Hamermesh and Pfann (1996) for a survey. Most of the existing studies dealing to the nonlinearity in unemployment tend to focus on the asymmetry over the business cycle: jobs disappear at a higher rate during recessions than expansions. Neftci (1984) had used unemployment series as a business cycle indicator where he investigated asymmetry of business cycles using a two-state Markov chain, see Clements and Krolzig (2003) for a survey. Rothman (1991), and Montgomery, Zarnowitz, Tsay and Tiao (1998) considered forecasting a US unemployment with nonlinear models. Hansen (1997) had fitted a TAR model to a US unemployment rate series. Koop and Potter (1999) had modeled US unemployment rate by applying Bayesian techniques to Threshold Autoregressive (TAR) models. The results of Skalin and Teràsvirta(2002) suggested that smooth transition autoregressive (STAR) models could capture well the asymmetry displayed in many OECD unemployment rate series : the series grows rapidly and decreases rather slowly. Milas and Rothman (2004) had used smooth transition vector error-correction models (STVECMs) in a simulated out-of-sample forecasting experiment for the unemployment rates of the the four countries, the U.S., U. K., Canada and Japan. Employing the two-state Markov regime switching model, Kano and Otha(2002) that the matching function changed frequently between increasing and constant returns regime, and expected durations were very short for both regimes. For these reasons, it seems that this kind of heterogeneity can be well specified in terms of PSTR model.

This solution simply consists introducing the threshold effect in linear panel model ( Hurlin et al., 2006, Fouqueau et al., 2008), Mignon, 2010). This model has been introduced by Gonzàles, Teràsvirta and Dijk (2005). It allow that the coefficients are a continuous functions of an observable variable through a bounded function of this variable, called the transition function, and fluctuate between limited numbers (often two) of "extreme regimes". In 
addition, the transition variable is individual-specific and time-varying.

$$
y_{t t}=\mu_{t}+\beta_{0}^{t} x_{t z}+\beta_{1}^{t} x_{t} g\left(s_{t,}, \gamma, c\right)+\varepsilon_{t t}
$$

With $t=1, \ldots, N$ and $t=1, \ldots, T$

$y_{t:}:$ is the dependent variable; $\mu_{i}:$ represents the fixed individual effects; $x_{i}: t s k$ dimensional vector of time-varying exogenous variable; $s_{i t}:$ are the errors; $G\left(s_{t t^{n}}, c\right)$ is a transition function, normalized and bounded between 0 and 1 and $s_{i t}$ the threshold transition. Following Granger and Teràsvirta (1993) and Teràsvirta(1994) and Gonzàles et al. (2005), the logistic specification can be used for the transition function:

$$
g\left(s_{i t}, \gamma, c\right)=\left(1+\exp \left(-\gamma\left(s_{t i}-c_{j}\right)\right)\right)^{-1}
$$

Where $\gamma \geqslant 0$ is the speed of transition and $c-\left(\varepsilon_{1}, c_{2}, \ldots \ldots, c_{m}\right)$ is a m-dimensional vector of threshold parameter.

Then, the PSTR model takes into account the change of parameters across regions and with time. This specification captures the space heterogeneity and time variability of coefficients, since these parameters vary smoothly according to the value of transition variable. More precisely, the coefficient is defined as a weighted average of parameters of extreme regime.

For our purposes, this model can evaluate the influence of transition variable on ht. Thus, we define different transitions variables in different specifications; we can evaluate the factor effects that could explain the cross-regions heterogeneity of $h_{i t}$.Indeed, the relationship can be interpreted according the regime and the transition function value. If tend towards 1 , the sum of the parameters correspond to affect values exogenous on $h_{i t}$. If $g\left(s_{t w} \psi_{t} c\right)$ tend towards 0 , the only $\beta_{0}$ represent the effect of these variable on hiring. Between the two extreme regimes, these coefficients are defined as the weighted average of vector parameters $\left(\beta_{Q}, \beta_{1}\right)$ by the transition function value. Hence, if the threshold variable $s_{i t}$ is different from the tension on labour market, the hiring sensibility for the $i^{\text {megion }}$ at time $\mathrm{t}$ is given by:

$$
\boldsymbol{e}_{t+t}=\frac{\partial h_{t t}}{\partial u_{t t}}=\beta_{0}^{1}+\beta_{1}^{1} * g\left(s_{t+N}, \psi_{,} c\right)
$$


For instance, if $\beta_{1}^{1}>0$, we have $\beta_{0}^{1} \leq \epsilon_{i t} \leq \beta_{0}^{1}+\beta_{1}^{1}$ or $\beta_{0}^{1}+\beta_{1}^{1} \leq \varepsilon_{t t} \leq \beta_{1}^{1}$ if $f_{1}^{1}<0$. Consequently, this PSTR model can evaluate the effect of the threshold variable of the hiring rate and to identify, indeed, the most important factors that could explain the cross-regions heterogeneity of the hiring variable.

Besides, it is important to note that it is not possible to interpret directly the parameters of the intermediate regimes. They does not correspond to the elasticity. But, according to Gonzàles (2004), it is simply possible to interpret the sign, which indicates a decrease or increase of $h_{i t}$ elasticity with the threshold value.

The PSTR model can be extended (with $\mathrm{r}+1$ regimes):

$$
y_{t z}=\mu_{t}+\beta_{0}^{l} x_{t t}+\sum_{f=1}^{\infty} \beta_{1}^{z} x_{t z} g\left(s_{t z}, \gamma_{t} c\right)+s_{t t}
$$

With $\mathrm{r}+1$ is a number of regime.

\section{Methodology and Specification Tests}

Following Gonzàles et al. (2005) the methodology suggests (i) to specify the model with specification tests, (ii) to estimate and (iii) to evaluate. In particular, the choice of the number of regimes is crucial, noted $r$. The first step of the specification is to test homogeneity (or linearity) against PSTR alternative. The second step is to select the number, of transitions functions (ie, the number of extremes regimes with equal to $\mathrm{r}+1$.

Testing homogeneity or linearity is defined by $H_{0} ; \gamma=0$ or $H_{0}^{m_{1}} \beta_{1}=0$. The both formulations tests are non standard because under $\boldsymbol{H}_{0}$ or $\boldsymbol{H}_{0}^{\mathrm{i}}$. The PSTR model contains unidentified nuisance parameters (the parameters of location c). To resolve this problem, following Lukkonenn, Saikonnen et Teràsvirta (1988) in time series, Gonzàles et al. (2005) in data panel proposed to replace the transition function $g\left(s_{k t}, \gamma, c\right)$ by its first -order expansion Taylor around $\gamma=0$ the auxiliary regression is represented by:

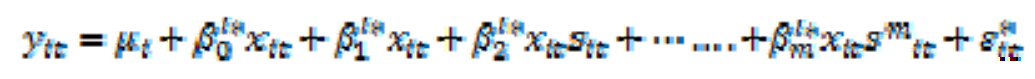

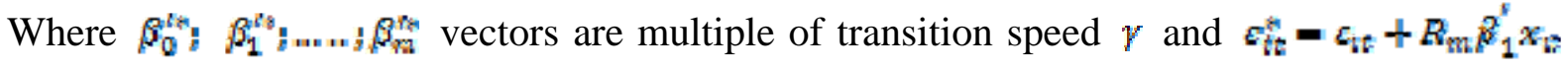
with $R_{m}$ is the remainder of the Taylor expansion. For instance, the null hypothesis becomes 


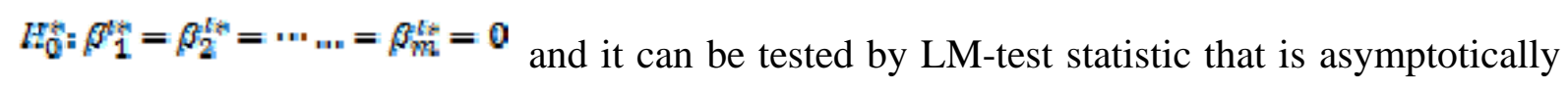
distributed as a $x^{2}(m k)$ under the null. If the number of observations is little, Gonzàles et al. (2005) proposed an alternative statistic test that asymptotically distributed as a $F\left(m k_{,} T N-m-k\right)$. If the linearity is rejected, the same test can be used (i) to select the appropriate the transition variable $s_{i t}$ that gives rise to the strongest rejection of linearity $\min p_{-}$value among a set of candidate variables (ii) to determine the optimal order $\mathrm{m}$ of transition function in 2 .

Estimation of the parameters of PSTR model consists to eliminating the individuals' effects $\mu_{i}$; by removing specific individual means and applying the non linear least squares to transformed model (see Gonzàles et al., 2005; Collàtez \& Hurlin, 2005). The estimation is very sensitive to the initial values (Gonzàles et al., 2005).

The step of the evaluation consists to testing firstly the hypothesis of non-remaining nonlinearity (or heterogeneity). When the linearity is rejected, this test is equivalent to testing PSTR with $r$ regimes against $r+1$ regime. For example, the idea is then to test whether there is one transition function $K_{2}: r=1$ or whether there are at least two transition function $\mathcal{E}_{1}: r=2$, the testing procedure continues until the first acceptance of $\boldsymbol{H}_{0}$. Therefore, in order to get sparse parsimonious and limit the number of transition function Gonzàles et al. (2005) propose to divide the significance level by a constant factor rho $=0.5$.

\section{Data and Results}

The data are yearly and concern 23 regions over the period 1984-2004. Our data are taken from INS (Statistic National institute), Tunisian Ministry of labor and regional labor offices.

\subsection{Stationary Tests}

For the preliminary results, we were interested to study the stationary of hiring, job seekers and vacant jobs series. Therefore, we apply the IPS and HADRI's tests for several specifications with the trend or not for one or two delay. The results are listed in the table below (Note 5). 
Table 1. IPS test

\begin{tabular}{|c|c|c|c|c|c|c|c|}
\hline & delay & $h_{i t}$ & $u_{i t}$ & $v_{i t}$ & $\Delta h_{i t}$ & $\Delta u_{i t}$ & $\Delta v_{i t}$ \\
\hline $\begin{array}{l}\text { With } \\
\text { trend }\end{array}$ & 0 & $\begin{array}{l}0-6.61 \\
(0.00)\end{array}$ & $\begin{array}{l}-4.65 \\
(0.00)\end{array}$ & $\begin{array}{l}-6.99 \\
(0.00)\end{array}$ & $\begin{array}{l}-17.77 \\
(0.00)\end{array}$ & $\begin{array}{r}-13.16 \\
(0.00)\end{array}$ & $\begin{array}{l}-18.92 \\
(0.00)\end{array}$ \\
\hline $\begin{array}{l}\text { With } \\
\text { trend }\end{array}$ & 1 & $\begin{array}{l}-1.54 \\
(0.00)\end{array}$ & $\begin{array}{l}-1.20 \\
(0.00)\end{array}$ & $\begin{array}{l}-1.22 \\
(0.00)\end{array}$ & $\begin{array}{l}-2.54 \\
(0.00)\end{array}$ & $\begin{array}{l}-4.77 \\
(0.00)\end{array}$ & $\begin{array}{l}-4.76 \\
(0.00)\end{array}$ \\
\hline $\begin{array}{l}\text { With } \\
\text { trend }\end{array}$ & 2 & $\begin{array}{l}-2.58 \\
(0.00)\end{array}$ & $\begin{array}{l}-6.97 \\
(0.00)\end{array}$ & $\begin{array}{l}-6.58 \\
(0.00)\end{array}$ & $\begin{array}{l}-7.58 \\
(0.00)\end{array}$ & $\begin{array}{l}-4.22 \\
(0.00)\end{array}$ & $\begin{array}{l}-3.15 \\
(0.00)\end{array}$ \\
\hline $\begin{array}{l}\text { Non } \\
\text { trend }\end{array}$ & 0 & $\begin{array}{l}-8.03 \\
(0.00)\end{array}$ & $\begin{array}{l}-5.65 \\
(0.00)\end{array}$ & $\begin{array}{l}-8.11 \\
(0.00)\end{array}$ & $\begin{array}{l}-8.03 \\
(0.00)\end{array}$ & $\begin{array}{l}-14.59 \\
(0.00)\end{array}$ & $\begin{array}{l}-20.16 \\
(0.00)\end{array}$ \\
\hline $\begin{array}{l}\text { Non } \\
\text { trend }\end{array}$ & 1 & $\begin{array}{l}-4.22 \\
(0.00)\end{array}$ & $\begin{array}{l}-4.32 \\
(0.00)\end{array}$ & $\begin{array}{l}-3.58 \\
(0.00)\end{array}$ & $\begin{array}{l}-4.22 \\
(0.00)\end{array}$ & $\begin{array}{l}-6.6 \\
(0.00)\end{array}$ & $\begin{array}{l}-6.59 \\
(0.00)\end{array}$ \\
\hline $\begin{array}{l}\text { Non } \\
\text { trend }\end{array}$ & 2 & $\begin{array}{l}-8.84 \\
(0.00)\end{array}$ & $\begin{array}{l}-6.97 \\
(0.00)\end{array}$ & $\begin{array}{l}-7.04 \\
(0.00)\end{array}$ & $\begin{array}{l}-8.84 \\
(0.00)\end{array}$ & $\begin{array}{l}-5.96 \\
(0.00)\end{array}$ & $\begin{array}{l}-4.94 \\
(0.00)\end{array}$ \\
\hline
\end{tabular}

The numbers in parenthesis are the p-value for different tests.

Table 2. Hadri test

\begin{tabular}{lllllll}
\hline & $h_{i t}$ & $u_{i t}$ & $v_{i t}$ & $\Delta h_{i t}$ & $\Delta u_{i t}$ & $\Delta v_{i t}$ \\
\hline $\begin{array}{l}\text { With } \\
\text { trend }\end{array}$ & 12.12 & 5.92 & 6.64 & -1.50 & -0.66 & -1.66 \\
Non & $(0.00)$ & $(0.00)$ & $(0.00)$ & $(0.93)$ & $(0.74)$ & $(0.95)$ \\
trend & 2.24 & 4.45 & 3.07 & -2.03 & -1.59 & -2.15 \\
& $(0.00)$ & $(0.00)$ & $(0.00)$ & $(0.97)$ & $(0.94)$ & $(0.98)$ \\
\hline
\end{tabular}

The numbers in parenthesis are the p-value for different tests. 
Regarding the results of Hadri tests, we have found that hires, Unemployment and Vacancy were all non stationary with integrated of order 1 . Moreover, the IPS test, conditional on the presence of the heterogeneity led us to reject the first hypothesis of non stationary. There is only exception for the the specification with order 1 and trend. This result entails some doubts about the validity of these tests which assumes a linear unit root test with a common autoregressive process while its persistence seems to be due to the heterogeneity between the regions.

\subsection{Linear Panel Model and Stochastic Frontier}

We propose in the table above, the results of four alternative specifications to the Tunisian matching process: the first column presents the estimation results stemming from a model with fixed effects, the second column shows the results of a model with random effects, the third watch the results deducted from the model of Battese and Coelli (1995) without specific effects where the heterogeneity across regions is introduced through the inefficiency series. The fourth specification combines the modeling of Battese and Coelli (1995) with that of the Greene (2005), named "true fixed-effects model", by the introduction of the specific effects for every region (Note 6).

Table 3. Parameters estimates of linear and stochastic frontier methods (Note 7)

\begin{tabular}{|c|c|c|c|c|}
\hline specification & Within & $\begin{array}{c}\text { Model with random } \\
\text { effects }\end{array}$ & $\begin{array}{l}\text { Stochastic } \\
\text { Frontier } \\
\text { (Battese and } \\
\text { Coelli) }\end{array}$ & $\begin{array}{c}\text { Stochastic } \\
\text { Frontier } \\
\text { (Grenne (2005)) }\end{array}$ \\
\hline \multirow[t]{2}{*}{$\beta_{0}^{1}$} & 0.06 & 0.06 & 0.08 & 0.12 \\
\hline & $(0.001)$ & $(0.08)$ & $(0.00)$ & $(0.02)$ \\
\hline \multirow[t]{2}{*}{$\beta_{1}^{1}$} & 0.640 & 0.86 & 0.89 & 0.8 \\
\hline & $(0.00)$ & $(0.00)$ & $(0.00)$ & $(0.00)$ \\
\hline Scale return & 0.7 & 0.92 & 0.97 & 0.92 \\
\hline Number of obs & 460 & 460 & 460 & 460 \\
\hline
\end{tabular}

The outcomes of this table conclude to a decreasing scale of return for the different specifications and the Tunisian labour market depend heavily on the vacancies stock. This implies a major inconvenience for regions with larger markets, in particular Tunis. This result contradicts the prediction of Blanchard and Diamond (1989) according to which we should 
expect a increasing return to scale in the urban labour markets, denser and more fluid nature.

\subsection{PSTR model and Choice of Transition Variable}

In the estimation phase of PSTR model, determining the threshold variable is a key issue. Knowing that the unemployment rate in Tunisia is more pronounced among the qualified younger than the unskilled middle age workers, is more noticeable among the women and is more serious in the North-west and southwest regions, we estimate thus a multivariate regression and we consider each of three potential structural factors in turn: the tension in labour market, the share of women seeking, and the education level. These variables are selected for divers reasons, discussed later in detail.

Focusing on empirical studies such as Fath and Sunde (2002, 2005), Ilmakunnas and Peosola (2003), Ibrouk et al (2001), we might introduce potential factors to capture the role of frictions in the matching process. We suppose that they have an asymmetric effect where the matching process and the labour market equilibrium conditions are at a regional level. First, we consider that the tension in labour market, noted $u_{t} / v_{t}$ as a transition variable. We are expecting that more the tension is strong; more the $h_{t}$ coefficients are higher. Several analysis support the idea of the implicit and the significant association between the tension variable and the matching process efficiency, although, there are different channels through in which this variable affects the labour market. Theoretical models of equilibrium unemployment often assumed that a constant returns to scale of the matching function, the hiring probabilities $h_{\tau} / v_{v}$ or $h_{\tau} / u_{\tau}$ depend only on the ratio of vacancy to unemployment ${ }^{u_{t}} / v_{t}$, and not on their size.

Some studies such as Blanchard and Diamond (1993), Burgess (1993), Anderson and Burgess (2000) have concluded that the job seekers intensity is the cause of regional variation in the matching efficiencies, although this effect may be quite different since regional relationship between supply and demand is specific. In order to take into account these interactions, Burgess and Profit (2001) analyzed the relationship between the cyclic variations and spatial distortions in the matching process in which they concluded that the employment search intensity depends on the local market situation and firm's behavior.

Thus, for low values of the transition variable $u_{t} / v_{t}$ when job seekers stock decreases. This generates a weak congestion in the employment market, a less heterogeneity and a better flow of information. For a given level of ${ }^{u_{v}} / v_{v}$, both parties (suppliers and job-seekers) would be "close"' and easily communicate each other with lower efforts and lower cost to a hiring compared to a higher tension market. Thus, it is easier for vacancies to find workers where we observe an improvement of hiring and a better matching efficiency. However, this is not 
the case if the local workforce lacks the formal skills to meet employers' needs (Kano and Ohta, 2005).

In contrast, strong values of transition variable due to an increase of $u_{\boldsymbol{t}}$ entails a decline of the probability to hiring in the region with a higher request. This obviously deteriorates the job search intensity. But the diminishing of $v_{t}$ informs us about the local labour market situation: generally an unfair wealth distribution between regions with the importance of mobility costs (Burda \& Profit, 1998).

In this case, conflicting evidence seems to be possible. The explanation is as follows: if the stock of job seekers is more diversified the probability that the companies to hiring may be strong. Cole and Smith (1996) have suggested that denser labour market could absorb the unfilled vacancies and the unemployed successfully. In terms of equilibrium unemployment theory, the market players enjoy a lower search cost.

Conversely, to check the negative relationship between unemployment and vacancy in Hong Kong labour market, known as the Beveridge curve, Tse et al. (2002) have found that under a large ratio ${ }^{u_{t /} / v_{t}}$, unemployed workers, has a considerable difficulty in finding jobs. Kano and Ohta (2005) have shown that in regions with a higher density, it is much more difficult to hiring, which entails lower matching efficiencies. The region characterized by a more different distribution of firms' hiring standards and workers' skill levels would exhibit a lower matching efficiency, due to higher possibility of conflicts between the requirements from both participants. This cause of regional variation in matching-efficiency due to the dispersion in the distribution of heterogeneous of the two parties "labour force and firms".

The second specification takes into account the impact of the share of women job-seekers in the matching process. Several studies associate the increase of the unemployment rate to increase of female participation in the labour market. Anderson and Burgess (2000) tried to check the regional heterogeneity by the introduction of age or sex variables in the working strength composition. Regarding the Tunisian labour market (BCT, 2007), Jamoussi and Gassab, 2011) have provided evidence for gender inequality and that the relationship between gender and unemployment is also significant. The same conclusion provided by Drin et al. (2011) of the significant and negative relation between the hiring rate and female participation. This analysis has supported the fact of the gender discrimination and the unemployment probability increase with female gender is a consistent result.

However, variables differently affect man's and woman's behaviors both quantitatively and qualitatively. It cannot be simply modeled through the use of uncomplicated gender-related dummy variables for explaining heterogeneity and geographical variations Figart(2005). More and more individual factors strongly interact with contextual factors in determining women employment.

Clark et al. (1999) discussed the relationship between culture, gender and the labour force for 
world zones. They founded that the Islamic women had the smallest share of the labour force. Antecol (2000) showed that the demography and job-seekers characteristics influence the cross-country female participation.

In addition, the district opportunities and women attitudes seem to play an important role in women insertion. Elhorst and Zeilstra (2007) developed the methodology to correct the occurrence of heterogeneity within groups. They showed that the employment opportunities in the local market are determined by the regional demand for labour and the sectoral market composition. However, expecting to access to optimal-position-level, a larger distance between the residence and firms has often a negative effect on the women insertion. Tabellini (2006) used a two-level Probit model to assess the factors which explain the socio-economic differences within Italian regions in the female regional participation such as: the regional civic program, regional macroeconomic conditions, the development of service sector, GDP growth etc.

Focusing on the Tunisian economic activity, an interesting characteristic that is almost 80 percent is male, while the women participation is still lower; the woman's employment becomes a major challenge. Since the independence, the feminine activity has been in a continuous growth, nearly 24 percent in 2004 compared to only 18 percent at the beginning of 1975. It is the highest in Kef, in Gabes and Kebelli, the opposite is true, in some locations where the clothing industry is widespread (INS, 2004).

The intensity of women seekers is generally related to the residence's proximity. In addition, the economic structure of the firms and the feminine personal characteristics have served to disqualify the women jobs more than they reveal their real ability and have led to a poor missmatch. The textile sector for example employed intensively female unskilled labor where the wage is inefficient.

In the third specification, the transition mechanism is based on the qualification rate. Theoretically, in the given region, more the qualified job-seekers is higher, more is efficient the matching. The probability of employment increases with the level of education, as it is easier for qualified job-seekers to find a job. But, the regional labor market is asymmetric and the distribution of firms reveals unbalances between the structures of labour supply and demand broken down by educational level, meaning that job-seekers lack the qualifications that employers needs. Kano and Ohta (2005) emphasize that the increase of the qualification heterogeneity in the regions with high-density in particular and the matching efficiency is negatively correlated with the degree of conflicts between firm's hiring standards and worker's skill level. In order to verify the role of qualification heterogeneity on the matching process, Entorf (1998), Van Ours and Ridder (1995), Berman (1997), Broersma and Van Ours (1999) have introduced it directly, into the estimation of the matching function and they concluded to a significant effect. More recently, several studies such as Lahtonen (2006) for Finland, Fahr and Sunde (2002) for Germany and Drin and Bouabid (2011) for Tunisia have showed that this effect is also significant and positive; an increase of qualified job seekers entails a increase of the efficiency. Indeed, a job with higher research intensity and better graduated to targeting their search increases the matching efficiency. 


\subsection{Estimation Results of PSTR Models}

For each model, the first step is to apply specification tests to test for linearity and non remaining linearity. The results are presented in table 4.

Table 4. Tests for remaining nonlinearity

\begin{tabular}{llll}
\hline Model & Model 1 & Model 2 & Model 3 \\
Threshold Variable & Tension & Women & Qualification \\
\hline$H_{0}: r=0$ us $H_{1}: r=1$ & 6.275 & 5.115 & 3.646 \\
& $(0.00)$ & $(0.00)$ & $(0.027)$ \\
$H_{0}: r=1$ vs $K_{1}: r=2$ & 2.291 & 1.114 & 1.902 \\
& $(0.059)$ & $(0.329)$ & $(0.109)$ \\
$H_{0}: r=2$ vs $H_{1}: r=3$ & - & - & - \\
\hline
\end{tabular}

The values in the parenthesis reported the p_value for linearity tests

For all specifications, the results of linearity tests and specification reject the linearity and the relationship between $h_{t}$ and $\left(v_{t} v_{t}\right)$ is a non linear of a threshold model type. The strongest rejection of the null hypothesis is obtained when the tension is considered as threshold variable. The optimal order of the transition function in different cases is $r=1$. In the previous model, the variables are only introduced as a transition variable. However, as Fouqueau and al (2008), the threshold transition may have a direct effect on the dependent variable. To check this point, a second test of non remaining linearity with direct effects, in which the threshold variable is used as an explanatory variable, is applied. Table 8 gives the results of test for remaining linearity with direct effects.

Table 5. Tests for remaining nonlinearity with direct effects

\begin{tabular}{llll}
\hline $\begin{array}{l}\text { Model } \\
\text { Threshold } \quad \begin{array}{l}\text { Model 1 } \\
\text { explicative variable }\end{array}\end{array}$ & $\begin{array}{l}\text { Tension } \\
\text { Women }\end{array}$ & $\begin{array}{c}\text { Model } 3 \\
\text { Qualification }\end{array}$ \\
\hline$H_{0}: r=0$ vs $H_{1}: r=1$ & 7.2301 & 6.2267 & 7.147 \\
& $(0.00)$ & $(0.00)$ & $(0.00)$ \\
\hline
\end{tabular}


In the second case, the null hypothesis of linearity is always rejected for all specifications. The linearity test shows that the strongest rejection is obtained from model 1 when tension as a transition variable. There is strong evidence in favor of our hypothesis where the relationship between hiring, vacancies and unemployment is nonlinear and that an analysis of the regional empirical matching models is more interesting. It turns that the Tunisian economy acts appears as a collection of some sub-labour markets, in which the underlying dynamics are specific and the equilibrium relations are distinct.

Hence, for a given region, it is possible that the dynamic of matching process changes with time, in response to potential structural change in control factors.

In particular, the region characterized by an increase of tension significantly increase the hiring sensibility with respect to $u_{t}$ and $v_{t}$ which improve the matching efficiency. However, the region with a little possibilities of requirements and the demand lack of the qualification exhibit lower matching efficiency, due to a higher heterogeneous unbalances between supply and demand. This latter finding is in line with the result of Tse et al. (2002), where a small $v_{v} / v_{v}$, firms will find a difficulty to recruit.

Tunisia is extremely characterized by unequal financial and economic policy among the regions although its growth strategy,. Limited to the coastal zones enjoyed by a higher growth than the southwest and the center regions. The gap also increased between regions, the Northwest and Center East, which benefited from the public sector as well as private investments in Tourism and offshore manufacturing, much closer to the capital city. In addition, this unemployment hit the qualified young job-seekers who has played a key role in fueling social unrest and actuated stress on the global employment market. Thus, the hardest-hit cities of Sidi-Bouzid, Kasserine and Thala in the country's center-west led the uprising against the regime and tipped over a political system. In this context, using a linear specification with homogenous sensibilities across regions may lead to fallacious estimates.

In addition, this specification is time-varying. We quote structural changes at 1996 particularly: Tunisia implemented two significant reforms to the labor code to improve labor market flexibility. Over the period 1984-2004, the results pointed out by Drin and Bouabid (2011) showed that the efficiency level varies between 0,4 and 0,95 and that the regions were more efficient in 1984 have become less advanced in 2004, while the regions with a lack of efficiency in 1984 have shown a improvement in 2004. Table 5 shows also the same result that the optimal number of regime is two and $r=1$. 
Table 6. Parameters estimates for the final PSTR

\begin{tabular}{lllll}
\hline Specification & Within & Model 1 & Model 2 & $\begin{array}{l}\text { Model 3 } \\
\text { Qualification }\end{array}$ \\
\hline$r^{*}$ & 1 & 1 & Women & 1 \\
$\beta_{0}^{1}$ & 0.006 & -0.4358 & 0.018 & 0.043 \\
& $(0.001)$ & $(0.011)$ & $(0.035)$ & $(0.079)$ \\
$\beta_{1}^{1}$ & 0.640 & 0.575 & 0.219 & 0.658 \\
& $(0.00)$ & $(0.109)$ & $(0.188)$ & $(0.092)$ \\
$\beta_{0}^{2}$ & & 0.531 & 0.0608 & 0.276 \\
& & $(0.141)$ & $(0.082)$ & $(0.008)$ \\
$\beta_{1}^{2}$ & & 0.23108 & 0.561 & 0.332 \\
& & $(0.0195)$ & $(0.0186)$ & $(0.0085)$ \\
C & & 1.1106 & 0.2262 & 0.0133 \\
$Y$ & & 46.46 & 65.665 & 130.7 \\
AIC Criterion & & -2.0443 & -2.2398 & -2.505 \\
Schwartz Criterion & & -1.9814 & -2.1859 & -2.511 \\
\hline
\end{tabular}

The numbers in brackets are Quasi-likelihood Standard Errors.

Table 7. Individual Elasticity of PSTR Estimates

\begin{tabular}{ccccccc}
\hline$s_{i t}$ & Tension & Tension & Women & Women & Qualification & Qualification \\
region & $u_{1 t}$ & $v_{1 t}$ & $u_{2 t}$ & $v_{2 t}$ & $u_{a t}$ & $v_{3 t}$ \\
\hline \multirow{2}{*}{ Tunis } & 0.2408 & 0.1438 & 0.0836 & 0.5866 & 0.1952 & 0.8415 \\
& $(0.160)$ & $(0.146)$ & $(0.1941)$ & $(0.2821)$ & $(0.1411)$ & $(0.1696)$ \\
\multirow{2}{*}{ Ben Arous } & 0.098 & 0.4533 & 0.0367 & 0.6548 & 0.1803 & 0.8236 \\
& $(0.197)$ & $(0.179)$ & $(0.029)$ & $(0.042)$ & $(0.1408)$ & $(0.169)$ \\
\multirow{2}{*}{ Ariana } & 0.042 & 0.3251 & 0.017 & 0.6833 & 0.1261 & 0.7418 \\
\hline
\end{tabular}


$\begin{array}{lllll}(0.22) & (0.1965) & (0.0029) & (0.0042) & (0.13)\end{array}$

\begin{tabular}{|c|c|c|c|c|c|c|}
\hline \multirow[t]{2}{*}{ Nabeul } & 0.08 & 0.4394 & 0.1492 & 0.4913 & 0.1122 & 0.7418 \\
\hline & $(0.22)$ & $(0.1965)$ & $(0.2083)$ & $(0.3027)$ & (0.1128) & $(0.1476)$ \\
\hline \multirow[t]{2}{*}{ Zaghouan } & -0.176 & 0.524 & 0.1092 & 0.5494 & 0.0431 & 0.6588 \\
\hline & (0.09) & $(0.083)$ & $(0.1103)$ & $(0.1603)$ & $(0.00)$ & $(0.00)$ \\
\hline \multirow[t]{2}{*}{ Bizerte } & 0.048 & 0.3199 & 0.0135 & 0.6885 & 0.0431 & 0.6588 \\
\hline & $(0.255)$ & $(0.233)$ & $(0.0047)$ & $(0.0068)$ & $(0.00)$ & $(0.00)$ \\
\hline \multirow[t]{2}{*}{ Beja } & 0.195 & 0.1853 & 0.2316 & 0.0249 & 0.0357 & 0.6878 \\
\hline & $(0.16)$ & $(0.15)$ & $(0.0083)$ & $(0.0121)$ & $(0.001)$ & $(0.00)$ \\
\hline \multirow[t]{2}{*}{ Jendouba } & 0.017 & 0.3794 & 0.0166 & 0.684 & 0.0283 & 0.6571 \\
\hline & $(0.25)$ & $(0.23)$ & $(0.0103)$ & $(0.015)$ & $(0.00)$ & $(0.00)$ \\
\hline \multirow[t]{2}{*}{ El Kef } & -0.137 & 0.4894 & 0.0184 & 0.684 & 0.0283 & 0.6571 \\
\hline & $(0.19)$ & $(0.18)$ & $(0.0108)$ & $(0.0157)$ & $(0.00)$ & $(0.00)$ \\
\hline \multirow[t]{2}{*}{ Siliana } & 0.0278 & 0.1098 & 0.0404 & 0.6495 & 0.0391 & 0.6581 \\
\hline & $(0.097)$ & $(0.096)$ & $(0.0267)$ & $(0.0388)$ & $(0.0003)$ & $(0.00)$ \\
\hline \multirow[t]{2}{*}{ Sousse } & 0.13 & 0.3616 & 0.0398 & 0.6503 & 0.1537 & 0.7917 \\
\hline & $(0.24)$ & $(0.22)$ & $(0.0189)$ & $(0.0275)$ & (0.139) & (0.167) \\
\hline \multirow[t]{2}{*}{ Monastir } & 0.064 & 0.4225 & 0.061 & 0.6194 & 0.1813 & 0.8249 \\
\hline & $(0.201)$ & $(0.18)$ & $(0.0547)$ & $(0.0794)$ & $(0.1418)$ & $(0.1704)$ \\
\hline \multirow[t]{2}{*}{ Mehdia } & 0.026 & 0.3404 & 0.2295 & 0.0257 & 0.0431 & 0.6588 \\
\hline & $(0.254)$ & $(0.23)$ & $(0.0194)$ & $(0.0281)$ & $(0.0008)$ & $(0.0008)$ \\
\hline \multirow[t]{2}{*}{ Sfax } & 0.24 & 0.3326 & 0.0156 & 0.6854 & 0.1256 & 0.8415 \\
\hline & $(0.168)$ & $(0.15)$ & $(0.0038)$ & $(0.0056)$ & $(0.1411)$ & $(0.1696)$ \\
\hline \multirow[t]{2}{*}{ Kairouan } & -1.121 & 0.4743 & 0.0137 & 0.6882 & 0.0431 & 0.6588 \\
\hline & $(0.158)$ & $(0.14)$ & $(0.0094)$ & $(0.0135)$ & $(0.00)$ & $(0.0005)$ \\
\hline \multirow[t]{2}{*}{ Kasserine } & -0.097 & 0.4531 & 0.0189 & 0.6807 & 0.0265 & 0.6588 \\
\hline & (0.192) & $(0.175)$ & $(0.0215)$ & $(0.0312)$ & $(0.0001)$ & $(0.000)$ \\
\hline \multirow[t]{2}{*}{ Sidi-Bouzid } & -0.124 & 0.4771 & 0.00163 & 0.6845 & 0.0364 & 0.6523 \\
\hline & $(0.165)$ & $(0.15)$ & $(0.0132)$ & $(0.0191)$ & $(0.000)$ & $(0.000)$ \\
\hline
\end{tabular}




$\begin{array}{ccccccc}\text { Gabes } & 0.053 & 0.3152 & 0.0127 & 0.6986 & 0.0569 & 0.6759 \\ & (0.222) & (0.21) & (0.0099) & (0.0618) & (0.0569) & (0.0743) \\ \text { Mednine } & -0.13 & 0.4861 & 0.0065 & 0.6986 & 0.0569 & 0.6754 \\ & (0.163) & (0.149) & (0.0043) & (0.0063) & (0.0613) & (00703) \\ \text { Tataouine } & 0.161 & 0.2171 & 0.0059 & 0.6996 & 0.0431 & 0.6588 \\ & (0.232) & (0.21) & (0.0031) & (0.0046) & (0.00) & (0.00) \\ \text { Gafsa } & -0.2 & 0.5471 & 0.012 & 0.6906 & 0.0846 & 0.7086 \\ & (0.119) & (0.11) & (0.0089) & (0.013) & (0.1013) & (0.1213) \\ \text { Tozeur } & -0.024 & 0.3857 & 0.0247 & 0.6721 & 0.0431 & 0.6588 \\ & (0.258) & (0.236) & (0.006) & (0.0087) & (0.00) & (0.00) \\ \text { Gbelli } & 0.155 & 0.2224 & 0.0125 & 0.6899 & 0.0708 & 0.692 \\ & (0.235) & (0.215) & (0.01) & (0.0146) & (00861) & (0.1023)\end{array}$

The numbers in brackets are Quasi Likelihood Standard Errors. For each region, the first line is the regional coefficient valuebeta. In the second line,() the standard deviation of Elasticities

Table 6 contains the parameter estimates of the final PSTR-model. The value of (speed) slope parameter gamma is high. Hence, all estimates of the hiring equation show that the transition from the lower region to the upper regime is smooth, but relatively rapid especially when the qualification is used as a transition variable. The value of estimated coefficient cannot be interpreted directly, but we can evaluate their signs. For example, if the sign of beta_\{1\} is positive, it implies that when transition variable is high, the hiring elasticity will increase. For instance, for the three models, our results show that the hiring elasticity on vacancies will rise, if tension, the share of women seekers and qualification rate are strong. But, a decrease of these variables bring down hiring

Furthermore, we conclude that the coefficients are more statistically significant and positive in the regime 1 as well as in the regime 2 for model 2 and the model 3 . This shows that the matching process is significant. But, it seems to be not consistent with the theory for model 1 in the case of low values of the tension variable. However, in the upper regime, this same coefficient appears more important for regions with a high tension. This corroborates the previous findings that a higher tension has a positive effect on the matching process where the returns to scale in this case around to 0.7 .

Again, we also find that the excess of graduated implies more effectiveness in the matching process while in lower regime we observe a lower positive effect. Hence, the increases of 
qualification improve the hiring. In line with the results of Drin et al (2011), we showed that a higher number of graduates in developing countries may have the same effect. Besides, Tunisia has built its growth strategy on low-skilled sectors and does not provide enough jobs for a new university-graduated. During the last decade, the workforce level has not been matched by a similar trend in labor demand which reflects one of the fundamental weaknesses of the Tunisian labour market.

With regard to the estimation of the linear methods of frontier stochastic, we note an increase of coefficient $\beta_{0}^{1}$ shows that the sensibility is more significant with PSTR model: the hiring seem, in this case, to be driven simultaneously by the stock of vacancies and the stock of job seekers and an important effect in the matching process. Although the difference of the previous studies (Ibrouk and Perelman, 2001, Drin et al., 2011), it turns out that our model permits to assess the relative importance of job seekers stock in the matching process, concluded on industrial countries. Our estimation appears to be "more successful" except for the first specification when the stock of job-seekers enters negatively in the matching function in the lower region.

In the second specification (model 2), we note that the coefficients are significant, positive and the threshold belongs to the interval of transition variable.

This result shows that the women insertion variable may be another explanation of regional disequilibrium and has a positive effect on the matching process (Fahr \& Sunde, 2002, 2006), Ilmakunnas \& Pesola, 2003) but the effect on the demand intensity is weakly pronounced, compared to the results of the first variable. A possible explanation can be brought through the residence's proximity and the employment nature. Although the trend in woman's educational attainment and the decline of fertility, the discrimination is present and the major of firms policies are against the women insertion. According to BCT in 2007, the gender parity ratio is increased from 1.1 in 2000 to 1.3 in 2005.

The third model 3 consider the specification of type LSTAR (1) whose the dynamic is logistic. Again, the dynamic of the lower regime is opposed to the upper regime. Hence, for a different level of qualification, the articulation between vocational and academic education, on a matching model basis, is asymmetric. The positive coefficient showed that the regions with higher graduated share are more efficient compared to regions with a small ratio. In fact, the Tunisian industrial tissue is rudimentary and the system is characterized by a massive number of the higher graduated and the lack of the adequate jobs with the demand of skilled labor comes mainly from the public sector. Since 1990, the structure between skilled and unskilled moved toward another trend. This fundamental change in the profile of new entrants was not accompanied by any significant transformation in labor demand. The difficulties to entry to the labour market are even greater for the graduated labour force, the unemployment rates among higher education have increased by 9 percent between 1975 and 2004. In particular, in the tertiary sector, the rate increased from 1.5 percent in 1984 to 10.2 percent in 2004, while gross unemployment has treated to stabilize. The reforms of 1991 and 2002, has been slow to materialize because of absence of information system and advice in schools. 
Furthermore, the private investment is low, and most of job opportunities, in Agriculture, textile industry and construction, it mainly provides for unskilled workers or low-skills while the policies in Tunisia focused often on attracting foreign direct investment requiring generally few graduate and induced the high-skilled to leave to Europe and the Golf state. More and more firms, tend to employ predominantly one specific type of qualification better jobs for higher skill are generated and at in the same time less skilled for workers could encounter greater difficulties in finding and retraining job for the same jobs (Rama (1995)).

The poor or rural regions of the discriminated zones (agriculture, mining) use mainly no-skilled or low-skilled labour with a lower wage, while others tend to employ primarily high-skilled workers, as the service sector and the communication. The high-skilled workers are more frequently in agglomerated areas because of their specific sector structure as well as urbanization and localization advantages. The skill structure is thus characterized by pronounced regional disparities and likely significant segregation between regions. Several empirical regional studies has shown that most urbanized markets are less efficient, Drin et al (2001) has introduced directly urbanization for each region as an additional variable and has confirmed its significant and negative effect on the matching process.

\subsection{Individual parameter PSTR Estimates}

Given the parameter estimates of the PSTR models for each transition variable, it is possible to calculate for each region and for each date the time varying hiring elasticities with respect to stock of job seekers and vacancies.

The outcome of the PSTR models in table 10 report the average estimated parameters based on the historical values of the transition variable $s_{i t}$ observed in the 23 regions. These values correspond to the mean and the variances of the individual estimates for each region. Even there, some remarks can be noticed from table 10 . When we consider the model 1 , the $h_{i t}$ elasticity to respect $u_{\boldsymbol{t}}$ is lower and different across regions and negative for 9 governorates among 23, especially in the agricultural zones such as ELkef, Zaghouan. The negative sign of unemployment-hiring sensibilities indicates that the matching process is not consistent with the underlying theory and might be biased.

We must assess the reliability of the data. It is often suggested that the number of jobs or unemployment registered could represent only a fraction of demand and offer in Tunisian labour market. One explanation is attributed to the market structure and the substantial activity of informal sector which have spillover effects on the formal sector and have biased the official statistics.

However, we observe, in the developed zone such as Tunis, Sfax, Sousse, an improvement of hiring sensibilities with respect to unemployment, due to an important role of job seekers intensity in the matching process. Thus, the responsiveness of the labour market depends indeed not only on the responsiveness of employers but also of the willingness of 
unemployed to fill jobs. Thus, this is evidence for the claim that in poor regions, it is a harder time in finding a match compared to industrial regions.

But the elasticity ${ }^{h_{i t}}$ to $v_{t}$ are positive with a different scale across regions of 0.1438 in Tunis due to the saturation effect where the biggest share of unemployed workers exist and performed by his own residents and those of others regions, which can act as an obstacle to landing job. This same coefficient closes to 0.6 for Gafsa, and 0.4771 for Sidi-Bouzid and 0.45 for Mednine. Furthermore, the important effect of vacancies in the Tunisian matching process seems more intense for disadvantaged zones when the responsiveness of these labour market depend only on the responsiveness of employers to fill vacancies with workers. It turns out that the employers also exercise greater caution and to be more selectiveness in filling their vacancies, which are generally insufficient with respect to job-seekers. In summary, the weakness of hiring sensibilities with respect to unemployment and vacancies show that the company badly had to find the appropriate profiles and the unemployed does not manage to reach the work which is appropriate to him.

The change in the elasticities across regions can be understood as the result of the heterogeneity of tension rate in different sub-markets when under a large $u_{v} / v_{\varepsilon}$ ratio, the firms will recruit more easily which improve the hiring rate.

For the second model, the ${ }^{h_{t}}$ sensibility on $u_{t}$ hold almost unchanged and low especially in the southern regions and high in Tunis while the $h_{i t}$ sensibility with respect to $v_{i t}$ are important and slightly different from a region to another. Even there, it is at the supply level that we observe the heterogeneous sensibilities since that the hiring process alters mainly with vacancies stock, while the willingness of feminine workforce has a lower effect on the matching process. Again, this finding is in favor of our hypothesis that the system shows a discrimination against the feminine insertion.

The labour participation rates observed are lower among the rural women than the urban women when the level of education in lower rates are higher, hence a strong rural-urban divide. The weakness of maternity leave regulation, the limited coverage provided by the child care system and woman's cultural factors may still make their contribution in social inequality. In addition, the Tunisian woman shows a strong preference for public sector as opposed to the private sector.

The same results are concluded for the third model, the sensibilities are positive and different. We note more particularly that the demand sensibilities are higher in the industrialized zones such as Tunis and Sfax compared to discriminated regions, whereas the same regions meet the fewer difficulties to create jobs for the graduated workforce. A novelty is that the sum of unemployment's and vacancy's elasticities is higher than one in Tunis, Sfax and Monastir, this implies a increasing scale to return, could lead to the existence of multiple» 'natural rates"' of unemployment (see, for example, Diamond, 1982) in the long run, where a lower 
unemployment occurs in the preferred equilibrium. The unemployed workers are thus combined with job vacancies, according to the supply-demand where the density plays a positive role and favors the hiring. However, for the regions with decreasing scale of return illustrate the inadequacy of Tunisian graduates labor markets. Neither the companies, nor the job seekers find easily her request. The offices intermeddle to regulate the flows of job-seekers by requiring the obstacles on the demand and to lower the market pressure.

The lowest sensibilities prove our hypothesis according to which despite this higher rate, the graduated job seekers have a slight effect on the matching efficiency. Jammoussi and Gassab (2011) showed that the graduated persons who have continued $\mathrm{PhD}$ studies to be more qualified, the chances to get employed has decreased largely.

Since the 90s, the Tunisian matching- process becomes more in more unmoved to the growth of the graduate size and the Tunisian policies has encouraged for long time the long studies in human and social sciences for decreasing the employment request.

These results show that the heterogeneity of the ${ }^{h_{t}}$ elasticities between the Tunisian regions and illustrate the advantage of the panel threshold approach.

Summing up, our interesting finding is that the hiring sensibilities on vacancies for the three models are always positive and superior to the demand sensibilities in all regions. This shows the important role of vacancies in the Tunisian matching process, contrary to the most findings on developed countries (Ibrouk et al., 2001). The significantly higher coefficient in the model for flows from registered vacancies could indeed be an indication for endogenous search behavior of employers with reality, a fact which makes their first attempt at labour market entry difficult.

Given this, the vacancies stock still has a positive effect on hiring in the Tunisian market where the economic situation was always for a long time with 3 percent growth rate and the employment elasticity on growth has been for many years above the international average (Kapsos, 2005). Thus, the frictions sources result mainly of the employment demand and its structure. This unemployment essentially concerns the youth, skilled and the women and it is linked more to the problem of insertion into the labour market (World Bank (2004)). The weakness of the sensibilities, in model 3 for example, shows that graduates, misinformed about the country's working conditions, have educational profiles that are inconsistent with reality, a fact which make their first attempt at labour market entry difficult.

The regions heterogeneity can be captured through the time varying estimates of $h_{t}$ parameters. We represent on figure 4, the individual estimates of parameters in model 1 with using the tension as a threshold variable which clearly leads to the strongest rejection of the linearity and varying sensibilities. On the figure 4, the individual estimates of the elasticities for the 23 regions are represented over the period 1985- 2004.

This means, plots have been done only for the "optimal" specification: model 1 because this model can better specify the cross-regions heterogeneity. We then choose tension as the 
threshold variable. The estimates of ${ }^{h_{t}}$ parameters are displayed in figure 1. These estimates

have been derived from equation (3). Looking at for all regions, the estimates of $h_{\boldsymbol{z}}$ parameters are bounded between 0.1 and 0.6 but with different dynamic over the considered period. For most of the regions, we observe in particular a peak at 1995-1996 followed by a fall of sensibility observed in 1999-2000, coinciding with the peak of unemployment rate at 16 percent level.
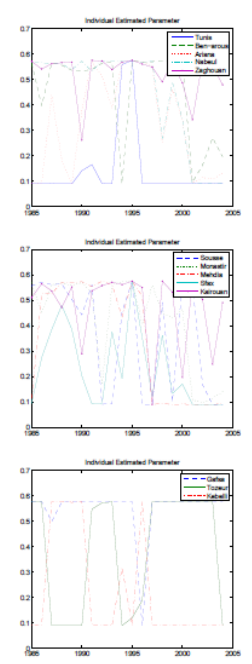

Figure 1. Individual estimated parameters

For Tunis and Sousse, the result is somewhat surprising and raises many interesting questions of constance of sensibilities over the period. A possible explanation is attributed to inability of the old Tunisian policies to change the sensibilities and improve the hiring. Hence, the unstable trend is observed in most disadvantaged zones where the fluctuations levels are more important over the time period. The main exception is concluded for Gafsa where the sensibilities are almost constant. The finding corroborates the results of Drin et al (2011) in which they showed this unstable trend over the same period. This means that the regions which were more efficient in 1984 has become less proficient in 2004 while the regions with a lower efficiency in 1984 have shown a improvement in 2004.

\section{Conclusion}

The objective of this paper is to analyze the regional disparities in the matching process of Tunisia during the 1984-2004 periods. On the basis of the Panel Smooth Transition Regression Model, our results showed that the hiring sensibilities change with time and across regions. More precisely several points were raised. First, we find that the tension, woman's integration and the qualification are three variables which have the greatest effect on the matching process.

Secondly, the hiring coefficients for 23 regions change according to the transition function of 
type logistic. This result reveals the strong heterogeneity in the matching process.Thirdly, the matching process of Tunisia is deriving essentially on the stock of vacancies, especially in rural zones in which the willingness of job seekers seems unimportant. This empirical framework, is based on new technique to identify the disparities in regional market dynamics, shows that Tunisia needs to undertake regional specific economic policies by feeding the regional growth to respond seriously to needs in each region and to favor the hiring. The challenges of the role of factors by improving the infrastructures for enhancing the workforce mobility and investigating policies measures directed and labour market reforms for every region requires, consequently, a precise analysis of regional characteristics (culture, qualification level, natural resources, etc...) to find the adequate investment and labour market reforms for improve the mismatch.

\section{References}

Albeak, K., \& Hansen, H. (2004). The rise in Danish unemployment: Reallocation or mismatch? CAM, 13.

Anderson, P., \& Burgess, S. (2000). Empirical matching functions: Estimation and interpretation using state-level data. The Review of Economics and Statistics, 82, 93-102. Antecol, H. (2000). An examination of cross-country differences in the gender gap in labor force participation rates. Labour Economics, 7, 409-426. https://doi.org/10.1016/S0927-5371(00)00007-5

Battese, G., \& Coelli, T. (1995). A model for technical efficiency effects in a stochastic frontier production function with panel data. Empirical Economics, 20, 325-332. https://doi.org/10.1007/BF01205442

Berman, E. (1997). Help wanted, job needed: Estimates of a matching function from employmentservice data. Journal of Labor Economics, 15, 251-291. https://doi.org/10.1086/209863

Blanchard, O. (1997). Labor-market flexibility and aggregate employment volatility: Acomment. Carnegie-Rochester Conference Series on Public Policy, 46, 229-239. https://doi.org/10.1016/S0167-2231(97)00009-2

Blanchard, O., \& Diamond, P. (1989). The beveridge curve. 13: Brookings Papers on Economic Activity.

Boubakri, M. (2010). Tunisie: Migration, marché du travail et développement. OIT: Institut International d_études Sociales, 1.

Broersma, L., \& Van Ours, J. (1999). Job searchers, job matches and the elasticity of matching labour. Economics, 6, 77-93.

Burda, M. (1993). Modeling exits from unemployment in eastern Germany: A matching function approach. CEPR Discussion Papers, 800.

Burda, M. (1994). Gross worker and job owns in Europe. European Economic Review, 38, 1287-1315. https://doi.org/10.1016/0014-2921(94)90076-0 
Burgess, S. (1993). A model of competition between unemployed and employed job searchers. Economic Journal, 103, 1190-1204. https://doi.org/10.2307/2234245

Burgess, S., \& Profit, S. (2001). Externalities in the matching of workers and firms in britain. Labour Economics, 8, 313-333. https://doi.org/10.1016/S0927-5371(01)00036-7

Caner, M., \& Hansen Bruce, E. (2001). Threshold autoregression with a unit root. Econometrica, 69, 1555-1596. https://doi.org/10.1111/1468-0262.00257

Clements, M. P., \& Krolzig, H. (2003). Business cycle asymmetries: Characterization and testing based on markov-switching autoregressions. Journal of Business and Economic Statistics, 21, 196-211. https://doi.org/10.1198/073500102288618892

Coles, M., \& Smith, E. (1996). Cross-section estimation of the matching function: Evidence from England and Wales. Economica, 63, 589-597. https://doi.org/10.2307/2554997

Colletàz, G., \& Hurlin, C. (2006). Threshold effects in the public capital productivity: An international panel smooth transition approach. Document de Recherche du Laboratoired' Economie d'Orléans, 1.

Da Costa, J., Cupertino, C. M., \& Galimberti, J. K. (2009). Explaining earnings persistence: A threshold autoregressive panel unit root approach. MPRA Paper, University Library of Munich, Germany, 14237.

Diamond, P. (1982). Wage determination and efficiency in search equilibrium. Review of Economic Studies, 49, 217-227. https://doi.org/10.2307/2297271

Drin, I., \& Bouabid, A. (2011). Efficiency frontier and matching process on the labor market: Evidence from Tunisia. Economic modeling, 28, 1132-1139.

Elhorst, P., \& Zeilstra, A. (2007). Labour force participation rates at the regional and national levels of the european union: An integrated analysis. Papers in Regional Science, 86, 525-549. https://doi.org/10.1111/j.1435-5957.2007.00136.x

Entorf, H. (1998). Mismatch Explanations of European Unemployment: A Critical Evaluation.

Fahr, R., \& Sunde, U. (2002). Estimation of occupational and stochastic production frontier models. IZA. Discussion paper, 552. https://doi.org/10.1080/00036840600685140

Fahr, R., \& Sunde, U. (2006). Regional dependencies in job creation: an efficiency analysis for western Germany. Applied Economics, Taylor and Francis Journals, 38.

Figart, D. (2005). Gender as more than a dummy variable: Feminist approaches to discrimination. Review of Social Economy, 4 5, https://doi.org/10.1080/00346769700000022

Fouqueau, J., Hurlin, C., \& Rabaud, I. (2008). The feldstein-horioka puzzle: A panel smooth transition regression approach. Economic Modeling, 5, 284-299. https://doi.org/10.1016/j.econmod.2007.06.008 
Gonz alès, A., Teràsvirta, T., \& Van Dijk, D. (2005). Panel smooth transition regression model. Working Paper Series in Economics and Finance, 604.

Granger, C. W. J., \& Teràsvirta, T. (1993). Modeling Non-Linear Economic Relationships. OUP Catalogue, Oxford University Press.

Greene, W. (2005). Reconsidering heterogeneity in panel data estimators of the stochastic frontier model. Journal of Econometrics, 126, 269-303. https://doi.org/10.1016/j.jeconom.2004.05.003

Hamermesh, D., \& Pfann, G. A. (1996). Adjustment costs in factor demand. Journal of Economic Literature, American Economic Association, 34, 1264-1292.

Hansen, B. (1997). Inference in TAR models. Studies in Nonlinear Dynamics and Econometrics. Berkeley Electronic Press, 2. https://doi.org/10.2202/1558-3708.1024

Ibrouk, A., Maillard, B., Perelman, S., \& Sneerees, H. (2001). The matching efficiency of regional labour markets: A stochastic production frontier estimation. The institute for the study of labor (IZA), 339.

Ilmakunnasand, P., \& Peosola, H. (2003). Regional labour market matching functions and efficiency analysis. Labour, 7, 413-437. https://doi.org/10.1111/1467-9914.00247

Lahtonen, J. (2006) Matching heterogeneous job seekers and vacancies: Empirical studies using Danish data. Jyvadskyla Studies in Business and Economics, 50.

Jackman, R., \& Roper, S. (1989). Regional labour market matching functions and efficiency analysis. Oxford Bulletin of Economics and Statistics, 51, 377-394. https://doi.org/10.1111/j.1468-0084.1989.mp51004002.x

Jamoussi, H., \& Gassab, M. (2011). Determinants of graduate unemployment in Tunisia. Almalaurea working paper, 16.

Kangasharju, A., Pehkonen, J., \& Pekkala, S. (2005). Returns to scale in a matching model: Evidence from disaggregated panel data. Applied Economics, 37, 115-118. https://doi.org/10.1080/00036840412331313530

Kano, S., \& Ohta, M. (2005). Estimating a matching function and regional matching e_ciencies. Japan and the World Economy, 17, 25-41. https://doi.org/10.1016/S0922-1425(03)00039-2

Kano, S., \& Ohta, M. (2011). An empirical matching function with regime switching: The japanese case. Institute of Policy and Planning Sciences, University of Tsukuba, Tsukuba, Japan, 967.

Koop, G., \& Potter, S. (1999). Dynamic asymmetries in U.S. unemployment. Journal of $\begin{array}{llll}\text { Business } \quad \text { and } \quad \text { Economic } & \text { Statistics, } & 17,\end{array}$ https://doi.org/10.1080/07350015.1999.10524819

Layard, R., Nickell, S., \& Jackman, R. (1996). Unemployment. Macroeconomic Performance 
and the labour Market. Oxford University Press, Oxford.

L'Horty, Y. (1997). Les flux entre emploi, chômage et inactivité: leurs effets sur les variations du chômage. Economie et Statistique, 306, 57-75. https://doi.org/10.3406/estat.1997.2573

Lin, C., \& Teràsvirta, T. (1994). Testing the constancy of regression parameters against continuous change. Journal of Econometrics, 62, 211-228. https://doi.org/10.1016/0304-4076(94)90022-1

Luukkonen, R., Saikkonen, \& Teràsivrta, T. (1988). Testing linearity against smooth transition autoregessive models. Biometrika, 383, 491-499. https://doi.org/10.1093/biomet/75.3.491

Mignon, V., Bérau, S., \& Lopez-Villavicencio, S. (2010). Nonlinear adjustment of the real exchange rate towards its equilibrium value: A panel smooth transition error correction modeling. Economic Modeling, 27, 404-416. https://doi.org/10.1016/j.econmod.2009.10.007

Mignon, V., \& Hurlin, C. (1994). Une synthèse des tests de cointégration sur données de panel. Document de recherche:Laboratoire d'Economie d'Orléans, 12.

Milas, C., \& Rothman, P. (2008). Out-of-sample forecasting of unemployment rates with pooled STVEM forecasts. International Journal of Forecasting, 24, 101-121. https://doi.org/10.1016/j.ijforecast.2007.12.003

Mijnich, D., \& Jurajda, S. (2003). Understanding long-term unemployment in the Czech Republic. Czech Journal of Economics and Finance, 53, 11-30.

Montgonery, L., Victor Zarnowitz, Ruey, S. T., \& George, C. T. (1998). Forecasting the U.S. unemployment rate. Journal of the American Statistical Association, 93, 478-493. https://doi.org/10.1080/01621459.1998.10473696

Nefti_gi, S. (1984). Are economic time series asymmetric over the business cycle? Journal of Political Economy, 92, 307-328.

Petrongolo, B., \& Pissarides, C. (2001). Looking into the black box: a survey of the matching function. Journal of Economic Literature, 39, 390-431. https://doi.org/10.1257/jel.39.2.390

Pissarides, C. (1986). Unemployment and vacancies in Britain. Economic Policy, 1, 499-559. https://doi.org/10.2307/1344583

Pissarides, C. (2000). Human capital and growth: A synthesis report. OECD Development Centre Working Papers, 168. https://doi.org/10.1787/372502181227

Rama, M. (1995). Do labor market policies and institutions matter? The adjustment experience in Latin America and the Caribbean. Labour, 243-268.

Rothman, P. (1991). Further evidence on the asymmetric behavior of unemployment rates over the business cycle. Journal of Macroeconomics, 13, 291-298. https://doi.org/10.1016/0164-0704(91)90057-2

Skalin, J., \& Teràsvirta, T. (2002). Modeling asymmetries and moving equilibria in 
unemployment rates. Macroeconomic Dynamics, 6, 202-241. https://doi.org/10.1017/S1365100502031024

Sneessens, H., \& Shadman-Mehta, F. (2002). Reflexions sur la persistance du chômage en Wallonie et en Flandret. in de la Croix D. et al., Capital humain et dualisme sur le marché du travail, de boeck.

Tabellini, G. (2010). Culture and institutions: Economic development in the regions of europe. Journal of the European Economic Association, 8, 677-716. https://doi.org/10.1111/j.1542-4774.2010.tb00537.x

Terasvirta, T. (1994). Specification, estimation, and evaluation of smooth transition autoregressive models. it International Journal of Forecasting, 18, 421-438. https://doi.org/10.1080/01621459.1994.10476462

Tse, C.Y.and Leung, C. and Chan, W. (2002). Unemployment and vacancy in the Hong Kong labour market. Applied Economics Letters, 9, 221-229. https://doi.org/10.1080/13504850110054959

Van Ours, J. (1995). An empirical note on employed and unemployed job search. Economics Letters, 49, 447-452. https://doi.org/10.1016/0165-1765(95)00695-C

Van Ours, J., \& Ridder, G. (1995). Job matching and job competition: Are lower educated workers at the back of queues? European Economic Review, 39, 1717-1731. https://doi.org/10.1016/0014-2921(95)00010-0

\section{Notes}

Note 1 . The period gap (t-1) is imputed to the deadline necessary for the realization of the matching between the supply and demand

Note 2. Like Pissaridies (2000), this assumption is needed to obtain a stationary unemployment rate.

Note 3. For time series, the changes in efficiency of matching-function and the presence of frictions in labour market pose considerable problems. In the contrary, the cross-sectional analysis is considered, for a long time, more appropriate to explain this quantitative change on the efficiency-level over time, but furthermore across sub-markets.

Note 4. Our findings, regardless of Hardri test, show that hires, Unemployment a Vacancy were all non stationary with integrated of order 1 . Moreover, the IPS test, conditional on the presence of heterogeneity led us to reject the first hypothesis of non stationary. This result sheds some doubts about the validity of these tests which assumes a linear unit root tests with a common autoregessive process and its (persistence) seems to be heterogeneous between the regions.

Note 5.The results are sensitive to the delays and to the presence or not of the trend. 


\section{Macrothink}

International Journal of Regional Development

ISSN 2373-9851 2017, Vol. 4, No. 1

Note 6. In this specification, we also add in the term of inefficiency a dummy variable ( D96), to estimate the effect of the institutional change at the level of the legislation and on the job protection from 1996, with the aim of producing flexible the Tunisian labor market by the introduction of contracts in definite durations and part-time work.

Note 7. In this table, We reproduce only the values of the coefficients of alpha and beta, for a more detailed presentation you can consult the thesis of Bouabid (2011).

\section{Copyright Disclaimer}

Copyright for this article is retained by the author(s), with first publication rights granted to the journal.

This is an open-access article distributed under the terms and conditions of the Creative Commons Attribution license (http://creativecommons.org/licenses/by/3.0/). 